\title{
Thermal Anomaly Detection of Industrial Zones with MNF and ICA
}

\author{
Enis Arslan*1 (D) \\ ${ }^{1}$ Cukurova University, Department of Computer Engineering, Adana, Turkey
}

\author{
Keywords \\ Land surface temperature \\ Thermal anomaly \\ Minimum noise fraction \\ Independent component \\ analysis
}

\begin{abstract}
Thermal anomalies can be detected with the help of the imagery provided by the satellite systems such as Advanced Spaceborne Thermal Emission and Reflection Radiometer (ASTER). ASTER provides five thermal bands for the effective analysis of thermal anomalies. In order to achieve this goal, considering the physical phenomena, many satellite signal processing methods and algorithms can be used. In this study, a region of steel facilities in the province of Hatay/Turkey is defined as the study area. Heat characteristics and extent of the area are represented by using four days of data from daytime and nighttime scenes. In order to define the thermal anomalies for the studied area, Land Surface Temperature (LST) was estimated by inverse Planck function approach for all TIR bands. Minimum Noise Fraction (MNF) and Independent Component Analysis (ICA) methods were applied on all thermal infrared (TIR) bands. The results of $\mathrm{MNF}$ and ICA components show location of the thermal anomalies for industrial complexes especially in nighttime scenes.
\end{abstract}

\section{INTRODUCTION}

The principal of remote sensing is to detect electromagnetic radiation emitted or reflected from the Earth in interaction with the atmosphere. TIR remote sensing techniques are commonly used in environmental studies and thermal anomaly detection (Coutts et al., 2016; Xia et al., 2018).

TIR energy emitted from vegetation, soil, water, minerals and rocks can be detected by the different regions of the electromagnetic spectrum using TIR bands. TIR sensors on a satellite system sense radiant temperature of an object that is related to its kinetic temperature. Sometimes these objects can be seen as a 'blackbody'. Blackbody is a hypothetical object which is a perfect energy absorber and emitter but at the same time which has no ability to reflect energy. It absorbs the whole spectrum regardless of the frequency. In fact, there is nothing as a blackbody but there are partial radiating objects like water, soil and rocks. By definition, emissivity is the ratio of the radiant flux emitted from an object to the value of the same object when accepted as a blackbody, which absorbs and emits all the energy at the same temperature and wavelength. For a blackbody, emissivity is nearly 1 while for a good conductor emissivity is nearly zero. Emissivity value is affected with the wavelength, surface roughness, water vapor absorption and density of the object (Handcock et al., 2012; Islam et al., 2016). Also, it is dependent on the viewing angle of the satellite and the sensor value. Emissivity value of an object can be between 0 and 1 (Handcock et al., 2012; Moore and Paine, 2014; Ndossi and Avdan, 2016; Jensen, 2020).

In order to compensate low radiation of thermal energy emitted from the objects, satellites with high resolution sensors are designed. Aerosols like hydrometeors of cloud and water vapor negatively affect the emitted electromagnetic signals by reducing the infrared energy on the absorption bands (Moore and Paine, 2014). So, atmospheric transmissivity should be taken into consideration in the sensor design and correction of TIR images for atmospheric conditions (Handcock et al., 2012). Satellite imagery composed of thermal, nearinfrared and visible bands can be used in LST estimation by using various algorithms. Split window algorithm (Wan and Dozier, 1996), single 
channel algorithm (Jiménez-Muñoz and Sobrino, 2003), inverse Planck function can be given as examples to these algorithms (Ndossi and Avdan, 2016). Radiance, Brightness temperature and Land surface emissivity are the intermediate calculation steps of the LST.

Thermal remote sensing has a variety of implementation areas such as geothermal activity (Darge et al., 2019; Gray et al., 2019; Hewson et al., 2020), coal fire research (Roy et al., 2015; Singh et al., 2020), earthquake forecasting (Ahmad et al., 2019; Wongpornchai and Suwanprasit, 2020) and heat island (Coolbaugh et al., 2007; Kuenzer et al., 2007; Wei et al., 2013; Moore and Paine, 2014; Saryschev et al., 2019). Moore and Paine (2014) studied concentrated points of heat release by using LST obtained from a different algorithm. Ndossi and Avdan (2016) studied on different algorithms to estimate LST from radiance image using ASTER data. Tiangco et al. (2008) carried out a research to derive land surface temperatures to determine the nighttime urban heat island effects. Rasul et al. (2017) reviewed researches for surface urban heat islands and surface urban cool islands.

In this study, LST was calculated by inverse Planck function as its simplicity for conversion. Minimum Noise Fraction (MNF) and Independent Component Analysis (ICA) methods were applied to TIR scenes in order to highlight thermal anomalies related with industrial factories in the study area. These methods can efficiently be used for point based thermal anomaly detection.

\section{STUDY AREA and ASTER DATA}

\subsection{Study Area}

The selected area mainly covers an industrial zone that operates on iron and steel in İskenderun city of Turkey's Hatay province. Four different areas in a square are selected in accordance with the ground truth data by using Google Earth as shown in Figure 1.

The geographic location is between with upper left latitude $36^{\circ} 46^{\prime} 20^{\prime \prime} \mathrm{N}$ and longitude $36^{\circ} 10^{\prime} 27^{\prime \prime} \mathrm{E}$, lower right latitude $36^{\circ} 39^{\prime} 19^{\prime \prime} \mathrm{N}$ and longitude $36^{\circ}$ $19^{\prime} 43^{\prime \prime}$.

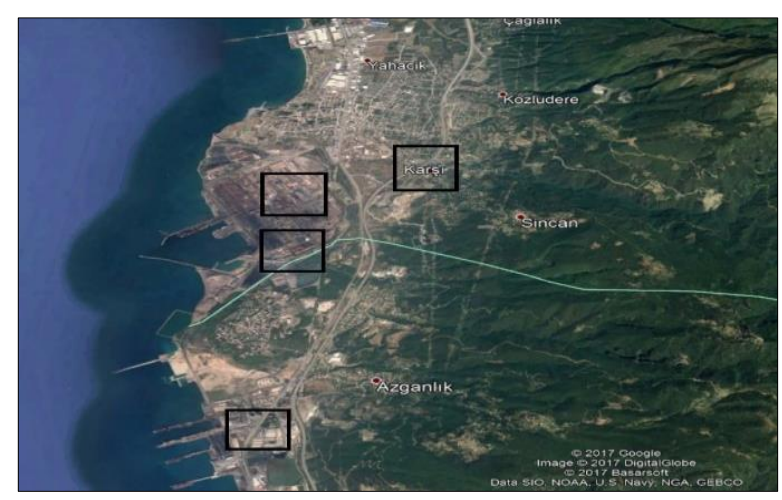

Figure 1. Google Earth image of the study area

\subsection{ASTER Data}

In this study, ASTER data that was obtained from Distributed Active Archive Center (DAAC) operated by U.S. Geological Survey (USGS) Earth Resources Observation and Science (EROS) Center and National Aeronautics and Space Administration (NASA) was used. ASTER is a satellite system that was launched in December 1999 as a product of NASA and Japan's Ministry of Economy developed with the aim of obtaining the land surface temperature, elevation, emissivity and reflectance data. Radiance at sensor of 15 bands is coded with digital numbers (DN). One band (Band $3 \mathrm{~B}$ ) is used for stereoscopic imagery while the other 14 bands are classified as: three bands in the visible and near infrared (VNIR), the six bands in the short wave (SWIR) and five TIR bands, with $15 \mathrm{~m}, 30 \mathrm{~m}$ and $90 \mathrm{~m}$ spatial resolution, 8 bit (0-255), 8 bit (0-255), 12 bit (0-4095) radiometric resolution and band numbers (1-3), (4-9), (10-14), respectively. The ASTER SWIR detectors are not functioning since April 2008 and SWIR data is available before that date.

The data is highlighted with the North-up map orientation and correction by Digital Elevation Model (DEM), radiometric correction, geometric correction with GLS2000 model and cross-talk correction applied to SWIR band. The details of the data are listed in Table 1 (Meyer et al., 2015).

Table 1. The ASTER data

\begin{tabular}{|c|c|c|c|}
\hline $\begin{array}{l}\text { Date } \\
\text { (Day, } \\
\text { Month } \\
\text { Year) }\end{array}$ & $\begin{array}{l}\text { Time } \\
\text { (Hour, } \\
\text { Minute, } \\
\text { Second) }\end{array}$ & Bands & $\begin{array}{l}\text { Spatial } \\
\text { resolution } \\
\text { (m) }\end{array}$ \\
\hline \multirow[t]{3}{*}{21.03 .2001} & 08:37:47 & VNIR & 15 \\
\hline & & SWIR & 30 \\
\hline & & TIR & 90 \\
\hline \multirow[t]{3}{*}{13.05 .2006} & 08:32:41 & VNIR & 15 \\
\hline & & SWIR & 30 \\
\hline & & TIR & 90 \\
\hline \multirow[t]{2}{*}{30.08 .2005} & $19: 35: 39$ & SWIR & 30 \\
\hline & & TIR & 90 \\
\hline 01.01 .2016 & $19: 36: 57$ & TIR & 90 \\
\hline
\end{tabular}

\section{MATHEMATICAL MODEL Of LAND SURFACE TEMPERATURE ESTIMATION}

Radiance value in DN are retrieved from TIR bands of AST_L1T Advanced Spaceborne Thermal Emission and Reflection Radiometer (ASTER) data. At first, the radiance value at the sensor is calculated. After that radiance value is converted to brightness temperature and it follows the conversion from brightness temperature to LST.

\subsection{Estimation of Radiance at Sensor}

In the beginning, given conversion coefficients (UCC) in Table 2 (Abrams et al., 2002) for the related AST_L1T thermal bands, registered radiance values 
at AST_L1T sensor in DN are converted to radiance at the sensor value in units of $\mathrm{W} /\left(\mathrm{m}^{2 *} \mathrm{sr}^{*} \mu \mathrm{m}\right)$ by using Equation (1).

Table 2. Unit conversion coefficients (UCC)

\begin{tabular}{lll}
\hline Band Number & \multicolumn{2}{l}{ Unit Conversion Table } \\
\cline { 2 - 3 } & High gain & Normal gain \\
\hline 1 & 0.676 & 1.688 \\
2 & 0.708 & 1.415 \\
3N & 0.423 & 0.862 \\
$3 \mathrm{~B}$ & 0.423 & 0.862 \\
4 & 0.1087 & 0.2174 \\
5 & 0.0348 & 0.0696 \\
6 & 0.0313 & 0.0625 \\
7 & 0.0299 & 0.0597 \\
8 & 0.0209 & 0.0417 \\
9 & 0.0159 & 0.0318 \\
10 & & 0.006822 \\
11 & & 0.006780 \\
12 & & 0.006590 \\
13 & & 0.005693 \\
14 & & 0.005225 \\
\hline
\end{tabular}

The radiance at sensor is given as:

$L_{\lambda}=(D N-1) \times U C C$

\subsection{Brightness Temperature}

Inverse Planck function is used to estimate brightness temperature as in Equation (2):

$$
T_{S n}=\frac{K_{2}}{\ln \left(\frac{K_{1}}{L_{\lambda}}+1\right)}
$$

In this equation, $T_{S n}$ is the brightness temperature, $L_{\lambda}$ is the top of atmosphere radiance (at sensor radiance), $K_{1}\left(W m^{2} s r^{-1} \mu m^{-1}\right)$ and $K_{2}\left(W m^{2} s r^{-1} \mu m^{-1}\right)$ are the coefficients, in Kelvin, for ASTER data as listed in Table 3 (Abrams et al., 2002).
Table 3. $K_{1}, K_{2}$ and $\lambda$ coefficients for ASTER data

\begin{tabular}{cccc}
\hline Band & $\mathrm{K}_{1}\left(\mathrm{Wm}^{2} \mathrm{sr}^{-1} \mu \mathrm{m}^{-1}\right)$ & $\mathrm{K}_{2}(\mathrm{~K})$ & $\begin{array}{c}\text { Effective } \\
\text { wavelength } \\
(\lambda) \text { in } \mu \mathrm{m}\end{array}$ \\
\hline 10 & 3047.47 & 1736.18 & 8.287 \\
11 & 2480.93 & 1666.21 & 8.685 \\
12 & 1930.80 & 1584.72 & 9.079 \\
13 & 865.65 & 1349.82 & 10.659 \\
14 & 649.60 & 1274.49 & 11.289 \\
\hline
\end{tabular}

\subsection{Land Surface Temperature Estimation}

Emissivity, brightness temperature and other atmospheric values are needed to calculate LST. Planck function, split window algorithm and single channel algorithm are a few of the various algorithms that can be used to calculate LST. LST is estimated by correcting the brightness temperature with the emissivity value as shown Equation (3):

$$
L S T=\frac{T_{s n}}{1+\frac{\lambda T_{s n}}{\rho} \ln \varepsilon}
$$

In this equation, LST is the land surface temperature in $\mathrm{K}, \rho$ is the $h \times$ $c / \sigma=1.438 \times 10^{-2} \mathrm{mK}, \lambda$ is the effective wavelength for the related band (Table 2) and $\varepsilon$ is the spectral emissivity. In this study, 0.96 value is used for $\varepsilon$ where it is chosen as an average of 0.94-0.97 used for a facility in (Moore and Paine, 2014).

\section{RESULTS and DISCUSSION}

In the first stage of the study, LST values were computed for five TIR bands using Equation 1, 2 and 3 respectively. It is aimed to define the high LST values related with the study area in the industrial zone. The selected area mainly covers an industrial zone that operates on iron and steel. Four different areas in a square are selected in accordance with the land observation and are validated with high LST values 


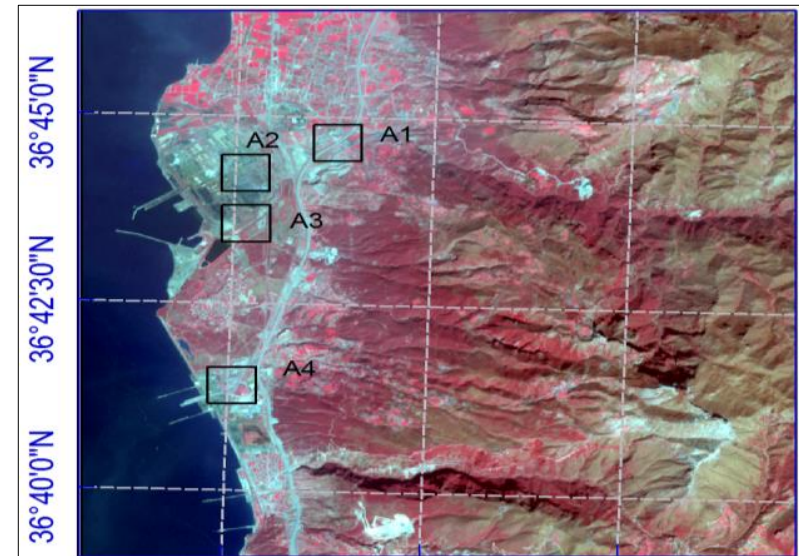

36 12 '30"E $\quad 36^{\circ} 15^{\prime} 0^{\prime \prime E} \quad 36^{\circ} 17^{\prime} 30^{\prime \prime E}$

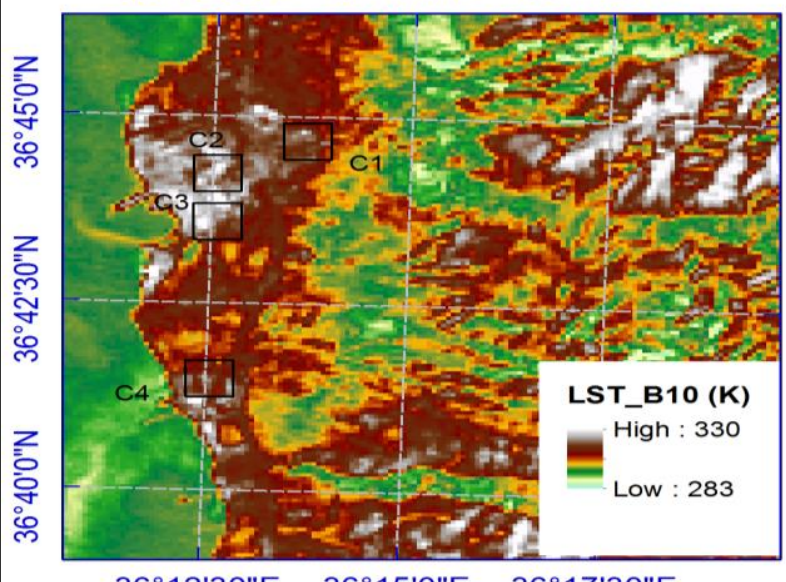

$36^{\circ} 12^{\prime} 30^{\prime \prime E} \quad 36^{\circ} 15^{\prime} O^{\prime \prime E} \quad 36^{\circ} 17^{\prime} 30^{\prime \prime E}$

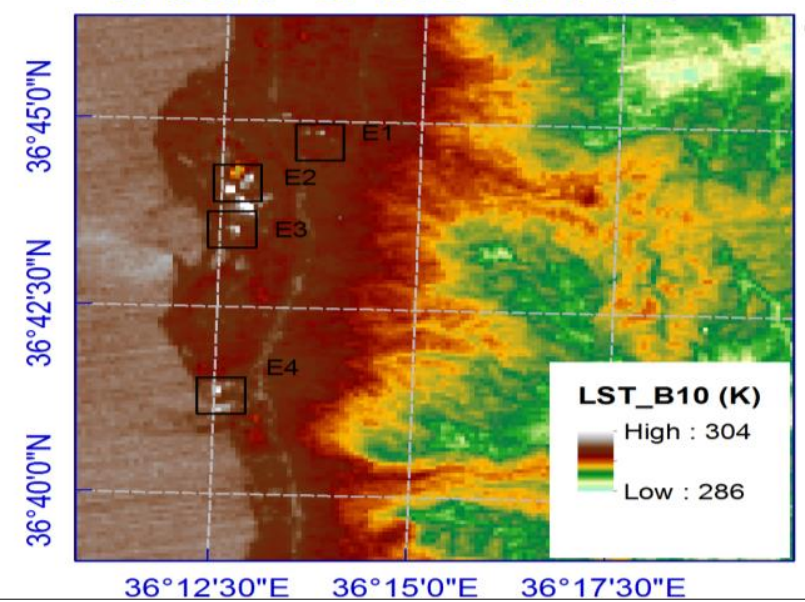

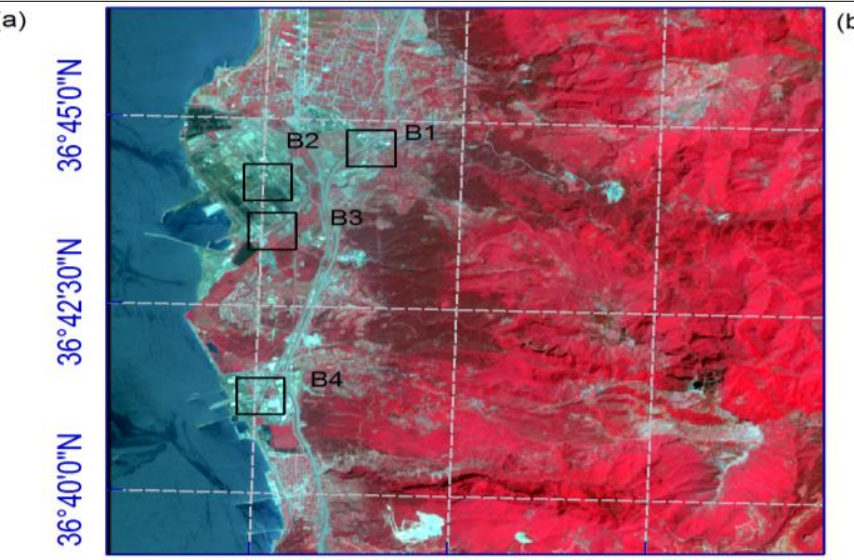

36 12'30"E $36^{\circ} 15^{\prime} 0^{\prime \prime E} \quad 36^{\circ} 17^{\prime} 30^{\prime \prime E}$

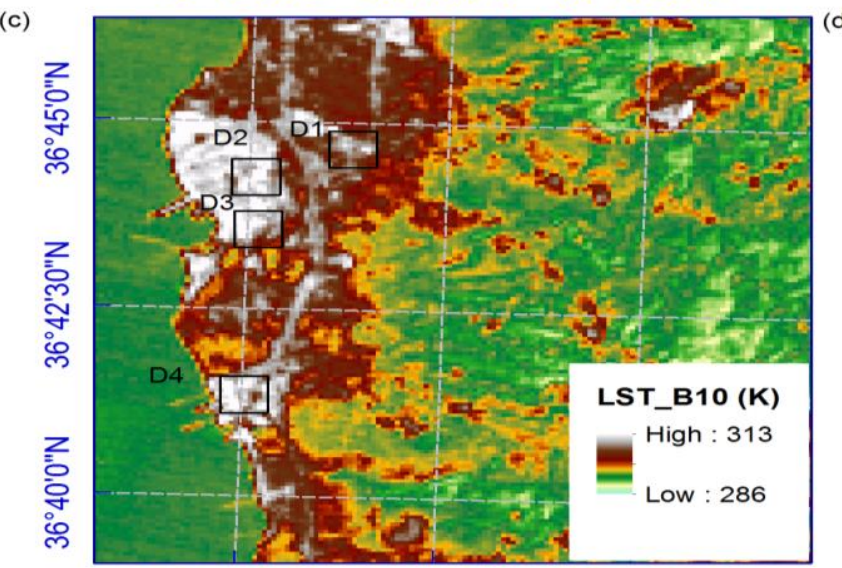

$36^{\circ} 12^{\prime} 30^{\prime \prime E} \quad 36^{\circ} 15^{\prime} 0^{\prime \prime E} \quad 36^{\circ} 17^{\prime} 30^{\prime \prime E}$

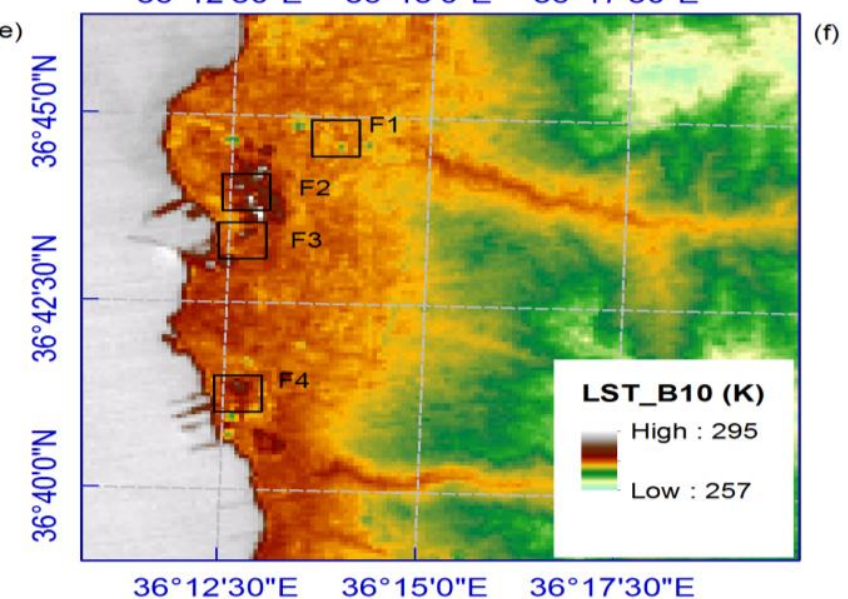

Figure 2. VNIR image of the study area (a) at 08:37:47 on 21.03.2001, (b) at 08:32:41 on 13.05.2006; LST values for TIR band10 (c) at 08:37:47 on 21.03.2001, (d) at 08:32:41 on 13.05.2006, (e) at 19:35:39 on 30.08.2005 and (f) at 19:36:57 on 01.01.2016

Figures $2 \mathrm{a}$ and $2 \mathrm{~b}$ depict that, VNIR image of the study area at 08:37:47 on 21.03 .2001 and at 08:32:41 on 13.05.2006, respectively. In these Figures, the high LST values are represented in squares from top to bottom as $\mathrm{A} 1, \mathrm{~A} 2, \mathrm{~A} 3$ and $\mathrm{A} 4$ (Figure 2a) and B1, B2, B3 and B4 (Figure 2b), respectively. In order to make comparison, two days from daytime and two days from nighttime image was selected. LST values only for band 10 is given in Figures $2 \mathrm{c}, 2 \mathrm{~d}, 2 \mathrm{e}$ and $2 \mathrm{f}$ at $08: 37: 47$ on 21.03.2001, at $08: 32: 41$ on 13.05 .2006 , at $19: 35: 39$ on 30.08.2005 and at 19:36:57 on 01.01.2016, respectively. LST values range from 283 to $330 \mathrm{~K}$ (Figure 2c), 286 to $313 \mathrm{~K}$ (Figure 2d), 286 to $304 \mathrm{~K}$ (Figure 2e) and 257 to $295 \mathrm{~K}$ (Figure 2f).

The values in the legends for the minimum are represented in turquoise and maximum is in white colour. Out of the squared region, there are widely white coloured areas that show maximum values in daytime image as $330 \mathrm{~K}$ (Figure 2c; C1, C2, C3 and C4) and $313 \mathrm{~K}$ (Figure 2d; D1, D2, D3 and D4). The track of the road can be seen in white colour in Figure $2 \mathrm{~d}$ and Figure $2 \mathrm{e}$. It is not easy to distinguish the industrial zones in the Figures $2 \mathrm{c}$ and $2 \mathrm{~d}$. The 
solar radiation coming from sun interacts with Earth and day of year affects the change of this LST values. As a result, interpretation of the daytime LST values are complex in behaviour because of this interaction.

The exact points of the thermal anomalies related with industrial zone can be seen from the nighttime image in Figure 2e (E1, E2, E3 and E4). The LST values as high as $304 \mathrm{~K}$ can be seen in white colour compared with the rest of the area. The similar results can be found in the other nighttime image that is given in Figure $2 f(F 1, F 2, F 3$ and F4). The nighttime image more clearly depicts the areas with high thermal anomalies relative to the daytime image. Because the encircled surface has higher temperature according to the neighbouring regions at night and focused points in the scene can be easily observed in 'white' for the industrial region with steel industry facilities.

In the second stage of the study, minimum noise fraction (MNF) analysis was applied to five thermal bands in order to determine thermal anomalies pointed out in Figures 2c, 2d, 2e and 2f. These anomalies can more clearly be determined in nighttime image as focused points (white). In order to make comparison, MNF analysis is applied to both daytime and nighttime thermal bands for the selected days. After the MNF transformation, image bands are noise reduced and decorrelated. In theory, MNF transformation is dependent on principal component analysis (PCA). In MNF, most of the information is included in the first two principal components.

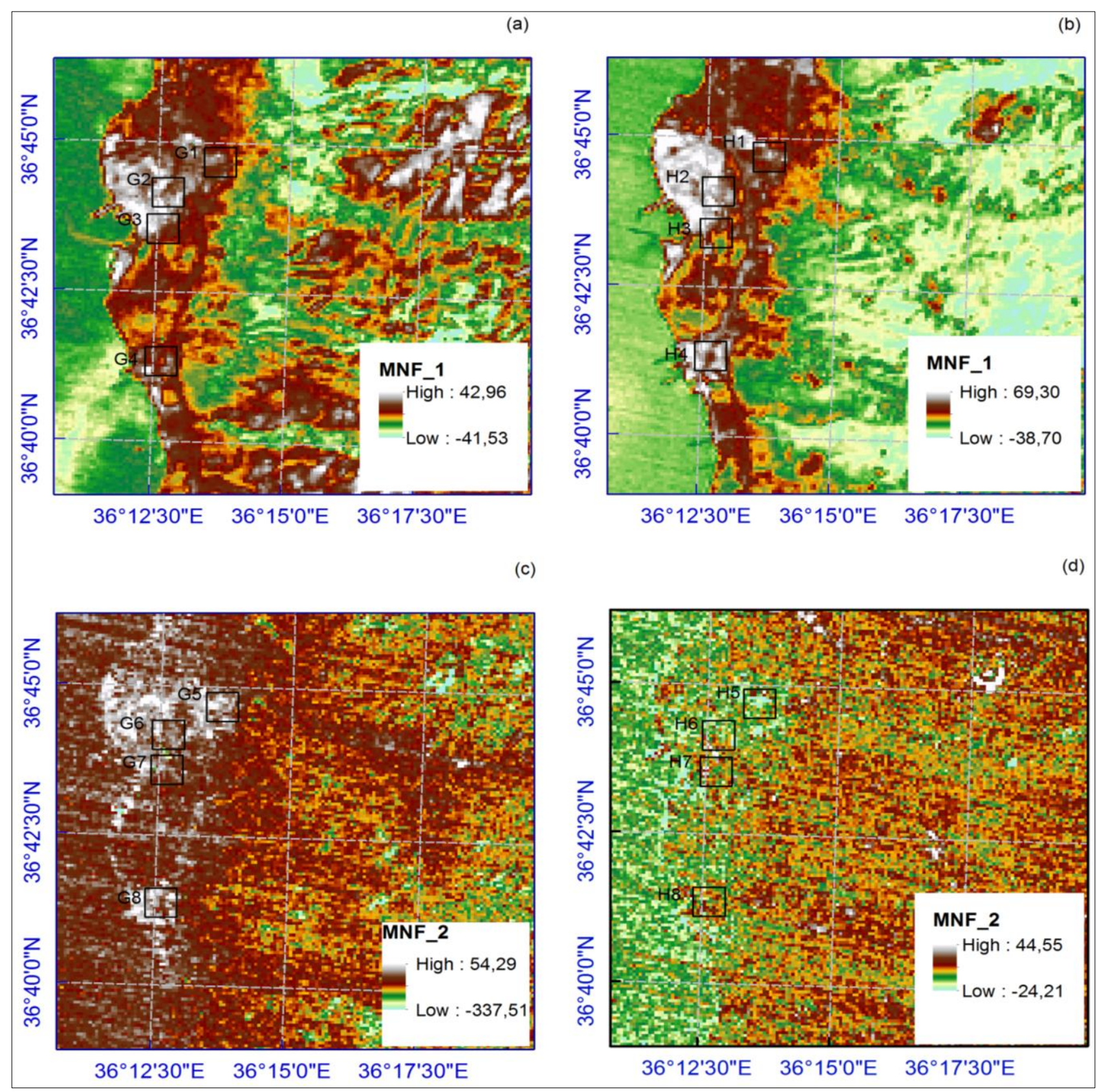

Figure 3. The first component of the MNF from the input of five thermal bands for daytime images (a) at 08:37:47 on 21.03.2001, (b) at 08:32:41 on 13.05.2006; The second component of the MNF from the input of five thermal bands for daytime images (c) at 08:37:47 on 21.03.2001, (d) at 08:32:41 on 13.05.2006 
Figures $3 \mathrm{a}$ and $3 \mathrm{~b}$ show the first components of the MNF transform for daytime images at 08:37:47 on 21.03.2001 and at 08:32:41 on 13.05.2006, respectively. The second components of the MNF are given at 08:37:47 on 21.03.2001 (Figures 3c) and at 08:32:41 on 13.05.2006 (Figures 3d) as well. These figures show that focused points showing steel industry facilities give high LST values because of the high temperature of furnaces. This effect represents itself as white point clusters in the images. The squared areas highlight this clusters. There are no exact focused points in daytime images whereas it shows localized points related with thermal anomalies as white coloured pixels (G1, G2, G3, G4, $\mathrm{H} 1, \mathrm{H} 2, \mathrm{H} 3$ and H4). Similar results can be found for the second MNF components (G5, G6, G7, G8, H5, H6, $\mathrm{H} 7$ and H8). The LST daytime image includes both solar radiation effect over steel factory and furnace temperature, it is not easy separate two effects from the figures.

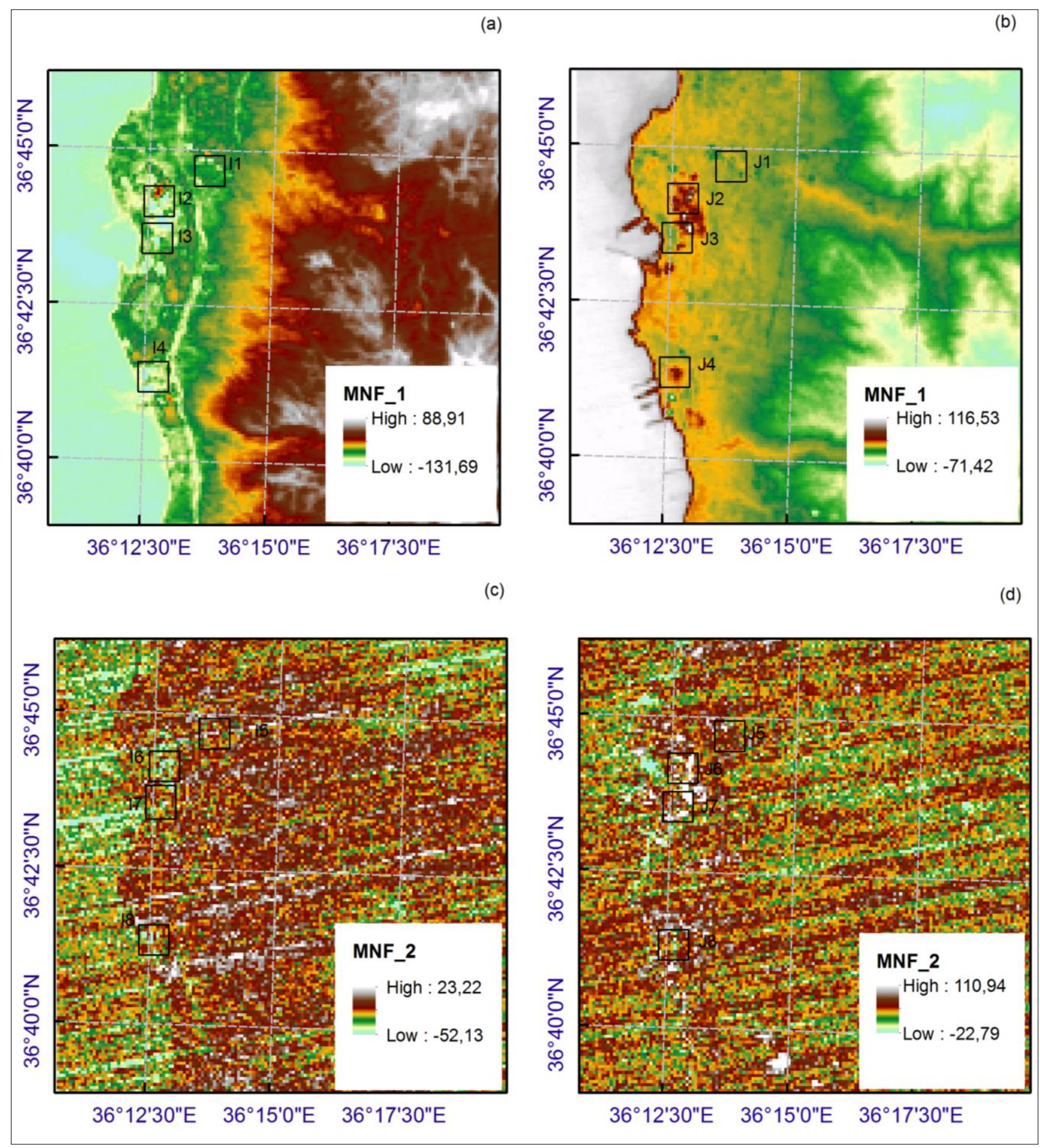

Figure 4. The first component of the MNF from the input of five thermal bands for nighttime images (a) at 19:35:39 on 30.08.2005, (b) at 19:36:57 on 01.01.2016; The second component of the MNF from the input of five thermal bands for nighttime images (c) at 19:35:39 on 30.08.2005, (d) at 19:36:57 on 01.01.2016 
Figures $4 \mathrm{a}$ and $4 \mathrm{~b}$ represent the first component of the MNF where Figures $4 \mathrm{c}$ and $4 \mathrm{~d}$ show the second component of the MNF for nighttime images at $19: 35: 39$ on 30.08 .2005 and at 19:36:57 on 01.01.2016, respectively. Thermal anomalies can be highlighted as focused points with white colour (Figure 4a; I1, I2, I3 and I4) and brown colour (Figure 4b; J2, J3 and J4) squares. There is no distinct area that shows thermal anomalies except J6 and J7 in second component of MNF in nighttime image.

In the last stage of the study, independent component analysis (ICA) was applied to five thermal bands in order to highlight thermal anomalies where results are represented in Figure 5. ICA analysis features the advantage of using mixed pixels when the anomalies are not evident and cannot easily be detected from the pixels. While principal component uses Gaussian statistics, ICA uses non-Gaussian statistics. ICA can be applied to multispectral remote sensing data and it can be successful even when the small part of the anomalies take place in a pixel. ICA uses mean, eigenvector, eigenvalue, principal component rotation to smooth the data.

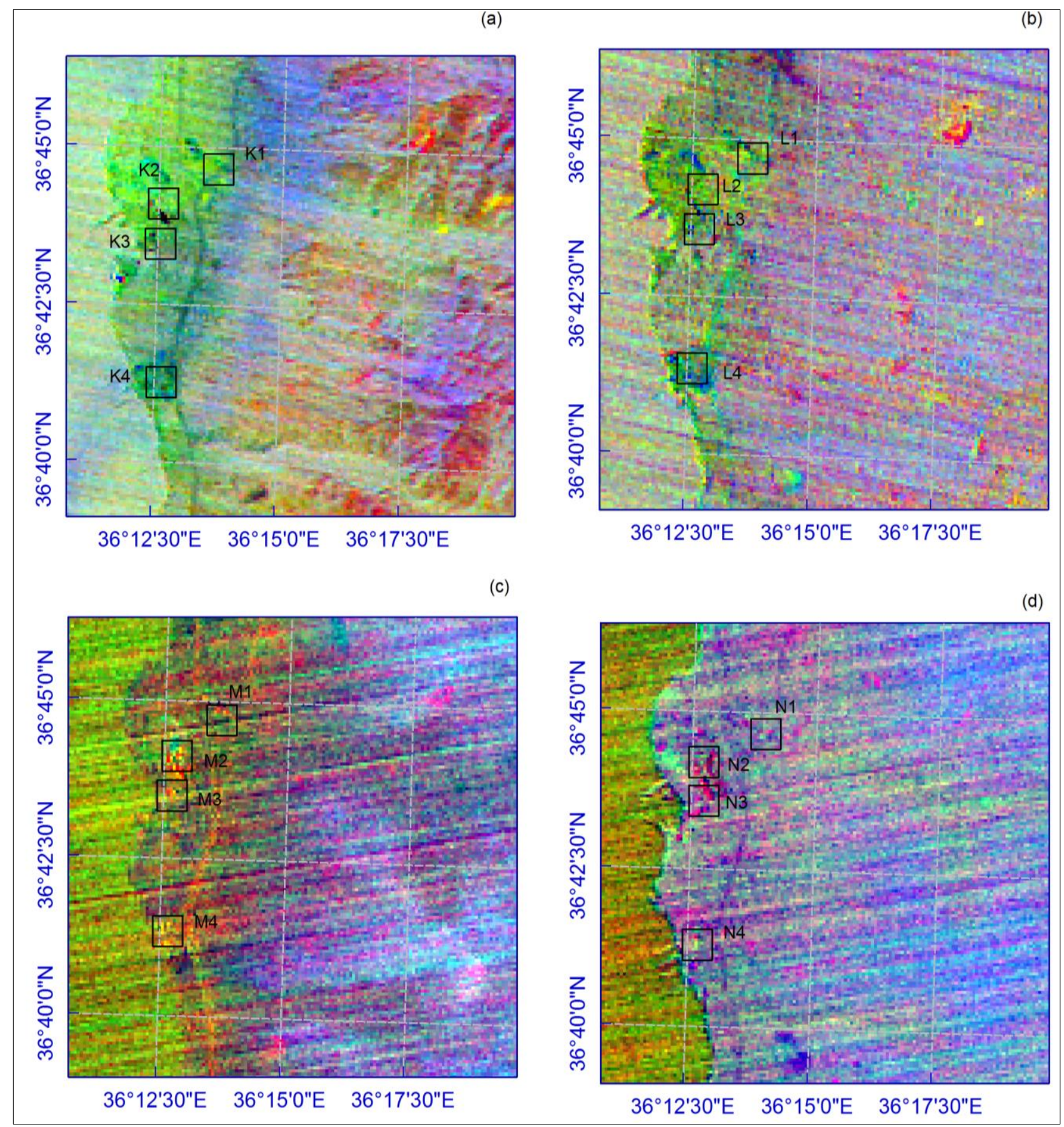

Figure 5. Red (IC3), green (IC2) and blue (IC1) band combination of the independent component analysis (ICA) of the five thermal bands (a) at 08:37:47 on 21.03.2001, (b) at 08:32:41 on 13.05.2006, (c) at 19:35:39 on 30.08.2005, (d) at 19:36:57 on 01.01.2016 
Figure 5a, 5b, 5c and 5d show Red (Independent component 3-IC3), green (Independent component 2-IC2) and blue (Independent component 1-IC1) band combination of the ICA at $08: 37: 47$ on 21.03.2001, at 08:32:41 on 13.05.2006, at 19:35:39 on 30.08.2005 and at 19:36:57 on 01.01.2016. For the daytime image in Figure 5a, black pixels in $\mathrm{K} 2$, $\mathrm{K} 3, \mathrm{~K} 4$ and for the nighttime images in Figure 5c, M1, M2, M3 and M4 exactly show thermal anomalies in yellow and red coloured in a squared region. The similar results can be found in Figure 4d with N1, N2, $\mathrm{N} 3$ and N4 as magenta and purple coloured in a square.

\section{CONCLUSION}

In this study, ASTER Thermal bands was used in order to highlight thermal anomalies in an industrial zone in İskenderun city of Turkey's Hatay province where steel industry facilities are common. Furnaces operating at high temperatures emit high radiation that can be sensed as thermal anomalies in satellite imagery.

In order to detect thermal anomalies represented by focused points in the imagery, two statistical methods as MNF and ICA are used. Four different sub-regions are determined for the daytime and nightime images for four distinct days.

At the first stage of the study, thermal anomalies in the sub-regions are verified by the calculation of LST with inverse Planck function. In the continuation of the study, MNF and ICA methods are applied to the same image data. It can be observed from the output of MNF method that the first component includes most of the information. When using this method, similar results representing the anomalies can be seen with a few exceptions. The last method, ICA, is applied to the same imagery data and 3 of the 5 bands are selected as Red (IC3) green (IC2) and blue (IC1) channels. ICA provides similar results as MNF method. Especially, nightime imagery shows distinct colour combinations for the sub-regions highlighting the thermal anomalies.

The application of MNF and ICA methods on the ASTER image data can be helpful in point based thermal anomaly detection in a selected region and the outputs of this study gives promising results to use these methods for this purpose.

\section{ACKNOWLEDGEMENT}

The ASTER L1T data product was retrieved from the online Data Pool, courtesy of the NASA Land Processes Distributed Active Archive Center (LP DAAC), USGS/Earth Resources Observation and Science (EROS) Center, Sioux Falls, South Dakota, (https://lpdaac.usgs.gov/data_access/data_ pool). This research did not receive any specific grant from funding agencies in the public, commercial, or not-for-profit sectors.

\section{REFERENCES}

Abrams, M., Hook, S., Ramachandran, B. (2002). ASTER user handbook, version 2. Jet propulsion laboratory, 4800, 135.

Ahmad, N., Barkat, A., Ali, A., Sultan, M., Rasul, K., Iqbal, Z., \& Iqbal, T. (2019). Investigation of spatio-temporal satellite thermal IR anomalies associated with the Awaran earthquake (Sep 24, 2013; M 7.7), Pakistan. Pure and Applied Geophysics, 176(8), 3533-3544.

Coolbaugh, M.F., Kratt, C., Fallacaro, A., Calvin, W.M., \& Taranik, J.V. (2007). Detection of geothermal anomalies using advanced spaceborne thermal emission and reflection radiometer (ASTER) thermal infrared images at Bradys Hot Springs, Nevada, USA. Remote Sensing of Environment, 106 (3), 350-359.

Coutts, A.M., Harris, R.J., Phan, T., Livesley, S.J., Williams, N.S., \& Tapper, N.J. (2016). Thermal infrared remote sensing of urban heat: Hotspots, vegetation, and an assessment of techniques for use in urban planning. Remote Sensing of Environment, 186, 637-651.

Darge, Y.M., Hailu, B.T., Muluneh, A.A., \& Kidane, T. (2019). Detection of geothermal anomalies using Landsat 8 TIRS data in Tulu Moye geothermal prospect, Main Ethiopian Rift. International Journal of Applied Earth Observation and Geoinformation, 74, 16-26.

Gray, D. M., Burton-Johnson, A., \& Fretwell, P.T. (2019). Evidence for a lava lake on Mt. Michael volcano, Saunders Island (South Sandwich Islands) from Landsat, Sentinel-2 and ASTER satellite imagery. Journal of Volcanology and Geothermal Research, 379, 60-71.

Handcock, R.N., Torgersen, C.E., Cherkauer, K.A., Gillespie, A.R., Tockner, K., Faux, R.N. Tan, J. (2012). Thermal infrared remote sensing of water temperature in riverine landscapes. Fluvial remote sensing for science and management, (85) 113.

Hewson, R., Mshiu, E., Hecker, C., van der Werff, H., van Ruitenbeek, F., Alkema, D., \& van der Meer, F. (2020). The application of day and night time ASTER satellite imagery for geothermal and mineral mapping in East Africa. International Journal of Applied Earth Observation and Geoinformation, 85, 101991.

Islam, T., Hulley, G.C., Malakar, N.K., Radocinski, R.G., Guillevic, P.C., \& Hook, S.J. (2016). A physicsbased algorithm for the simultaneous retrieval of land surface temperature and emissivity from VIIRS thermal infrared data. IEEE Transactions 
on Geoscience and Remote Sensing, 55(1), 563576.

Jensen, J.R. (2020). Thermal Infrared Remote Sensing Department of Geography, Lecture Notes, University of South Carolina. Retrieved from www.gers.uprm.edu/geol6225/pdfs/06_therm al_rs.pdf

Jiménez-Muñoz, J.C., Sobrino, J.A. (2003). A generalized single-channel method for retrieving land surface temperature from remote sensing data.Journal of Geophysical Research: Atmospheres, 108(D22).

Kuenzer, C., Zhang, J., Li, J., Voigt, S., Mehl, H., \& Wagner, W. (2007). Detecting unknown coal fires: synergy of automated coal fire risk area delineation and improved thermal anomaly extraction. International Journal of Remote Sensing, 28(20), 4561-4585.

Meyer, D., Siemonsma, D., Brooks, B., Johnson, L., (2015). Advanced Spaceborne Thermal Emission and Reflection Radiometer Level 1 Precision Terrain Corrected Registered At-Sensor Radiance (AST_L1T) Product, Algorithm Theoretical Basis Document (No. 2015-1171). US Geological Survey.

Moore, G., Paine, R. (2014). Quantifying urban-rural temperature differences for industrial complexes using thermal satellite data. AECOM: accessed, 15, 2018.

Ndossi, M.I., Avdan, U. (2016). Inversion of land surface temperature (LST) using Terra ASTER data: A comparison of three algorithms. Remote Sensing, 2016, 8(12), 993.

Rasul, A., Heiko, B., Claire, S., John, R., Bashir, A., José A. S., Manat, S., \& Qihao, W. (2017). A Review on remote sensing of urban heat and cool islands. Land 6, (2) 38.

Roy, P., Guha, A., \& Kumar, K.V. (2015). An approach of surface coal fire detection from ASTER and
Landsat-8 thermal data: Jharia coal field, India. International journal of applied earth observation and geoinformation, 39, 120-127.

Saryschev, D.V., Kurolap, S.A., \& Popova, I.V. (2019). Verification of Urban Heat Island Microclimatic Model by Using Thermal Remote Sensing Data. In IOP Conference Series: Earth and Environmental Science (Vol. 272, No. 2, p. 022085). IOP Publishing.

Singh, N., Chatterjee, R. S., Kumar, D., Panigrahi, D.C., \& Mujawdiya, R. (2020). Retrieval of precise land surface temperature from ASTER nighttime thermal infrared data by split window algorithm for improved coal fire detection in Jharia Coalfield, India. Geocarto International, 118.

Tiangco, M.A., Lagmay, M.F., \& Argete, J. (2008). ASTER-based study of the night-time urban heat island effect in Metro Manila. International Journal of Remote Sensing 29, no. 10: 27992818.

Xia, H., Chen, Y., \& Quan, J. (2018). A simple method based on the thermal anomaly index to detect industrial heat sources. International journal of applied earth observation and geoinformation, 73, 627-637.

Wan, Z., Dozier, J. (1996). A generalized split-window algorithm for retrieving land-surface temperature from space. IEEE Transactions on geoscience and remote sensing, 34(4), 892-905.

Wei, C., Zhang, Y., Guo, X., Hui, S., Qin, M., \& Zhang, Y. (2013). Thermal Infrared Anomalies of Several Strong Earthquakes. The Scientific World Journal.

Wongpornchai, P., Suwanprasit, C. (2020). Feasibility study of thermal anomaly detection for earthquake: A case study from 2014 Mae Lao earthquake, Thailand. In IOP Conference Series: Earth and Environmental Science (Vol. 538, No. 1, p. 012034). IOP Publishing. 